\title{
Histomorphological analysis of placental changes of pre-eclampsia patients in a tertiary care hospital of Puducherry, India
}

\author{
Rupal Samal $^{1 *}$, Anandraj Vaithy K. ${ }^{1}$, S. Sowmya ${ }^{2}$
}

\begin{abstract}
${ }^{1}$ Department of Obstetrics and Gynecology, Mahatma Gandhi Medical College and Research Institute, Sri Balaji Vidyapeeth, Puducherry, India

${ }^{2}$ Department of Pathology, Mahatma Gandhi Medical College and Research Institute, Sri Balaji Vidyapeeth, Puducherry, India
\end{abstract}

Received: 20 March 2020

Accepted: 20 April 2020

*Correspondence:

Dr. Rupal Samal,

E-mail: rupalsamal1@yahoo.co.in

Copyright: (c) the author(s), publisher and licensee Medip Academy. This is an open-access article distributed under the terms of the Creative Commons Attribution Non-Commercial License, which permits unrestricted non-commercial use, distribution, and reproduction in any medium, provided the original work is properly cited.

\begin{abstract}
Background: Placenta is a dynamic tissue synthesized physiologically to serve as a nutrient source for developing fetus it is exposed to several changes in reaction to many toxemic conditions associated with pregnancies. Studies had proved that placental changes observed on histomorphology is directly proportional to reaction to hemodynamic compensatory mechanisms, thereby aiding the obstetricians to manage the sequelae of complications. Objective of this study was to study the placental histomorphology in pregnancies associated with pre-eclampsia and to quantitate the observed placental changes.

Methods: The study comprised on 101 placental specimens obtained from department of obstetrics and gynecology, Mahatma Gandhi Medical College and Research Institute, Pondicherry. Toxemia of pregnancies were divided into mild, severe preeclampsia and eclampsia based on blood pressure. The 101 cases were divided as 4 groups: Group 1 (control group); Group 2 (mild preeclampsia); Group 3 (severe preeclampsia); Group 4 (eclampsia).

Results: Among the 101 cases, 38 placentas were from uncomplicated full-term deliveries which constitutes the control group. The rest 63 placenta were from toxemia of pregnancies which constitutes the study group.

Conclusions: The incidence of toxemic pregnancies and pre-eclamptic cases are on higher margin than assumed. Histomorphology examination of placenta plays a vital role in assessing etiopathogenesis and mechanism of toxemic pregnancies. This aids the obstetrician to further manage subsequent sequelae and fix the complication to significant proportion.
\end{abstract}

Keywords: Histopathological changes, Placental changes, Pre-eclampsia, Toxemia

\section{INTRODUCTION}

Placenta being a dynamic tissue synthesized physiologically to serve as a nutrient source for developing fetus, many a instance, it happens to be a platform to several degenerative changes depending upon the pregnancy associated morbidities. ${ }^{1,2}$ Toxemia of pregnancy is a condition characterized by multisystem disorder involving hypertension during gestational period, proteinuria and triggering of coagulation cascade and its pathways with adjunction of hepatic and renal morbidities. ${ }^{3,4}$ Both morphological and functional dearrangements of placenta has a significant impact in fetal development and serves as a tool to categorize healthy status of the fetal development. ${ }^{5}$

Overall it has been estimated that maternal hypertension is being diagnosed in 9 to 10 percentage of all deliveries and among that 20 to 25 percent of all perinatal deaths occurs. ${ }^{6}$ Several studies have been carried out on analysing placenta in toxemic pregnancies but most of the studies were inclined towards clinical evaluation rather 
than clinic-pathological correlation. The reason owing to the cause is that the obstetricians clears off the placental tissue after conduction of delivery often obviating to subject it for further histopathological examinations. ${ }^{7-9}$ Prior studies conducted on placental analysis of histomorphology have reported regarding the placental abnormalities both macroscopical as well as microscopical examination in pre-eclampsia pregnancies which includes alteration in structure of villous vasculature, significant thickening of basement membrane, proliferation of cytotrophoblasts and degenerative changes like villous fibrinoid necrosis. ${ }^{10-12}$ All these findings are documented as a reaction to compensatory mechanism to the disturbance in hemodynamics system. ${ }^{13}$

Since the placenta serves as a bridge between mother and fetus, the histomorphological examination of placenta gives a guidance to analyse underlying etiopathogenesis and what is anticipated to occur with the fetus in the future thereby aids the obstetrician to manage subsequent sequelae of events. ${ }^{14-16}$ With literature back up, the present study was carried out with a aim to study the placental histomorphology in pregnancies associated with pre-eclampsia and to quantitate the placental changes observed on histomorphology patterns.

\section{METHODS}

The study comprised on 101 placental specimens obtained from department of obstetrics and gynecology, Mahatma Gandhi Medical College and Research Institute, SBV University, Pondicherry, India. Among the 101 cases, 38 placentas were from uncomplicated fullterm deliveries which constitutes the control group. The rest 63 placenta were from toxemia of pregnancies which constitutes the study group.

\section{Inclusion criteria}

- All pregnant females admitting for safe confinement to labour room who crossed gestational age of 34 weeks duration irrespective of parameters like age and parity.

\section{Exclusion criteria}

- Conditions like twin pregnancy, gestational diabetes, cardiac complications, autoimmune and chronic illness conditions were excluded from the study.

Toxemia of pregnancies were divided into mild, severe preeclampsia and eclampsia based on the blood pressure recorded more than $140 / 90 \mathrm{mmHg}$ after 28 weeks of gestation with or without edema, and/or proteinuria and convulsions.

\section{The 101 cases were categorized into 4 groups}

- Group 1 (Control group)
- Group 2 (Mild preeclampsia)

- Group 3 (Severe preeclampsia)

- Group 4 (Eclampsia).

The collected unfixed placentas were washed and weighed before formalin fixation. The gross placental changes were absorbed and quantified using semi quantitative methods as;
A. 'Absent'- when no lesion was noticed on gross inspection.
B. '十'-- gross lesion was focally distributed.
C. '十+'-extensive lesions.

Secondary changes like infarction and perivillous fibrin deposits were quantified based on the surface area of involvement and were further confirmed by histology on light microscopic examination. Bits were taken from core central, peripheral areas and any grossly visible pathological changes

The sections were processed and stained with haematoxylin and eosin stain as per standard operating protocol of the institute. Approximately seventy-five to one hundred villous structures were picked up, examined and counted from the sections and pathological changes on light microscopy were expressed in terms of percentage. As an adjunct factor, special stains like periodic acid Schiff (PAS), Van Gieson were applied in warranted cases based on histomorphology.

\section{RESULTS}

Overall, 101 cases were studied including both control and study groups. The study analysed women of reproductive age groups starting from $2^{\text {nd }}$ decade to $4^{\text {th }}$ decade of life. Primi cases and multiparous cases were analysed. The number of placentas were categorized into 4 different groups and it included 38 cases in Group 1, 27 in Group 2, 27 in Group 3 and 9 cases in Group 4. The placenta was weighed with standard calibrated weighing machine and the one from severe pre-eclamptic cases weighed lesser than 480 grams whereas normal placentas weighed more than 600 grams. The dimensions of the placentas were recorded in standards of centimetres and the one from toxemic pregnancies ranged lesser than 3 cms and the umbilical cord ranged between 15 to $22 \mathrm{cms}$ in length.

The placental morphometric parameters are depicted in Table 1.

Gross examination of the placentas included various parameters indicating underlying pathological conditions. Sub-chorionic deposition of fibrin which indicates alteration maternal blood flow to fetus was observed in 6 cases in Group 1, 2 cases in Group 2, 6 cases in Group 3 and 1 case in Group 4. Infarction which indicates tissue reaction to altered blood supply was seen in 12 cases in Group 1 but the grade was less severe ranging $<10 \%$. 
Whereas in other groups it ranged $>25 \%$ of surface in Group 2 to 4. Calcification which indicates secondary changes were seen more among normal controls rather than toxemic cases (Figure 1). The incidence of gross abnormalities in all the 4 Groups were tabulated in Table
2 in terms of numbers. The overall observations indicated that gross abnormalities were profoundly seen among placentas from toxemic pregnancies due to hemodynamic disorders with a significant $\mathrm{p}$-value $(<0.002)$.

Table 1: Placental morphometric study.

\begin{tabular}{|lllll|}
\hline Placental parameters & Group 1 $(\mathbf{n = 3 8})$ & Group 2 $(\mathbf{n = 2 7})$ & Group 3 $(\mathbf{n = 2 7})$ & Group 4 $(\mathbf{n = 9})$ \\
\hline Placental weight $(\mathrm{gms})$ & $478.80 \pm 292.12$ & $438.90 \pm 66.15$ & $374 \pm 87.59$ & $333.86 \pm 120.53$ \\
\hline Thickness $(\mathrm{cm})$ & $2.75 \pm 0.34$ & $2.02 \pm 0.43$ & $1.99 \pm 0.49$ & $1.77 \pm 0.42$ \\
\hline
\end{tabular}

Table 2: Gross placental changes.

\begin{tabular}{|c|c|c|c|c|}
\hline Gross placental changes & Group $1(n=38)$ & Group $2(n=27)$ & Group $3(n=27)$ & Group $4(n=9)$ \\
\hline \multicolumn{5}{|l|}{ Subchorionic fibrin deposit } \\
\hline Absent & 32 & 24 & 21 & 8 \\
\hline+ & 3 & 1 & 1 & 1 \\
\hline++ & 3 & 1 & 1 & - \\
\hline \multicolumn{5}{|l|}{ Infarction } \\
\hline $0-4 \%$ & 8 & - & - & - \\
\hline $5-9 \%$ & 4 & 2 & 4 & - \\
\hline $10-25 \%$ & - & 4 & 7 & 1 \\
\hline$>25 \%$ & - & 6 & 10 & 5 \\
\hline \multicolumn{5}{|l|}{ Perivillous fibrin deposit } \\
\hline $0-4 \%$ & 2 & 2 & - & - \\
\hline $5-9 \%$ & - & 4 & 2 & - \\
\hline $10-25 \%$ & - & 6 & 9 & 6 \\
\hline$>25 \%$ & - & 3 & 10 & 1 \\
\hline \multicolumn{5}{|l|}{ Intervillous thrombus } \\
\hline Absent & 36 & 19 & 9 & 4 \\
\hline+ & - & 6 & 2 & - \\
\hline++ & 2 & 2 & 16 & 5 \\
\hline \multicolumn{5}{|l|}{ Calcification } \\
\hline Absent & 15 & 22 & 19 & 7 \\
\hline+ & 20 & 1 & 3 & 2 \\
\hline++ & 3 & 4 & 5 & - \\
\hline Retroplacental hematoma & - & - & $3(11.11 \%)$ & $2(22.22 \%)$ \\
\hline
\end{tabular}

Table 3: Villous lesions of the placenta.

\begin{tabular}{|c|c|c|c|c|}
\hline Villous lesions & Group $1(n=38)$ & Group 2 (n=27) & Group $3(n=27)$ & Group $4(n=9)$ \\
\hline \multicolumn{5}{|l|}{ Villous vascularity } \\
\hline Normal & $37(97.3 \%)$ & $9(33.33 \%)$ & 1 & 2 \\
\hline Increased & $01(26.3 \%)$ & $2(7.40 \%)$ & 2 & - \\
\hline Decreased & - & $16(59.2 \%)$ & 24 & 7 \\
\hline \multicolumn{5}{|c|}{ Cytotrophoblastic proliferation } \\
\hline$<20 \%$ & $38(100 \%)$ & $9(33.33 \%)$ & - & - \\
\hline $20-40 \%$ & - & $17(62.96 \%)$ & $17(62.96 \%)$ & - \\
\hline$>40 \%$ & - & $1(3.7 \%)$ & $10(37 \%)$ & $9(100 \%)$ \\
\hline \multicolumn{5}{|c|}{ Basement membrane thickening } \\
\hline$<3 \%$ & - & $21(77.77 \%)$ & $6(22.22 \%)$ & - \\
\hline$>3 \%$ & - & $5(18.5 \%)$ & $21(77.77 \%)$ & $9(100 \%)$ \\
\hline \multicolumn{5}{|c|}{ Vasculosyncitio membrane } \\
\hline$<6 \%$ & - & $22(81.4 \%)$ & $27(100 \%)$ & $9(100 \%)$ \\
\hline $6-30 \%$ & $12(31.5 \%)$ & $2(0.54 \%)$ & - & - \\
\hline$>30 \%$ & $11(28.9 \%)$ & - & - & - \\
\hline Endarteritis obliterans & - & 5 & 22 & 9 \\
\hline
\end{tabular}


Table 4: Degenerative changes in villous on histomorphology.

\begin{tabular}{|c|c|c|c|c|}
\hline Villous lesions & $\begin{array}{l}\text { Group } 1(n=38) \\
\text { ( } \% \text { of cases) }\end{array}$ & $\begin{array}{l}\text { Group } 2(n=27) \\
\text { ( } \% \text { of cases) }\end{array}$ & $\begin{array}{l}\text { Group } 3(n=27) \\
\text { ( } \% \text { of cases) }\end{array}$ & $\begin{array}{l}\text { Group } 4(n=9) \\
\text { (\% of cases) }\end{array}$ \\
\hline \multicolumn{5}{|l|}{ Syncytial knots } \\
\hline$<30 \%$ & $20(52.6 \%)$ & $6(22.22 \%)$ & - & - \\
\hline $30-50 \%$ & $18(47.3 \%)$ & $20(74 \%)$ & $15(55.55 \%)$ & - \\
\hline$>50 \%$ & - & $1(3.7 \%)$ & $11(40.7 \%)$ & $3(33.33 \%)$ \\
\hline$>90 \%$ & - & - & $1(3.7 \%)$ & $6(66.66 \%)$ \\
\hline \multicolumn{5}{|l|}{ Villous stromal fibrosis } \\
\hline$<6$ & $31(81.5 \%)$ & $18(66.66 \%)$ & $3(11.11 \%)$ & $1(11.1 \%)$ \\
\hline$>6$ & - & $5(18.51 \%)$ & $23(85.18 \%)$ & $8(88.88 \%)$ \\
\hline \multicolumn{5}{|l|}{ Fibrinoid necrosis } \\
\hline$<3$ & $24(63.15 \%)$ & $14(51.8 \%)$ & - & - \\
\hline$>3$ & $10(26.31 \%)$ & $11(40.7 \%)$ & $26(96.2 \%)$ & $6(66.66 \%)$ \\
\hline$>10$ & - & - & $1(3.7 \%)$ & $3(33.33 \%)$ \\
\hline Intervillous hemorrhage & - & $4(14.8 \%)$ & $13(48.14 \%)$ & $4(44.44 \%)$ \\
\hline
\end{tabular}

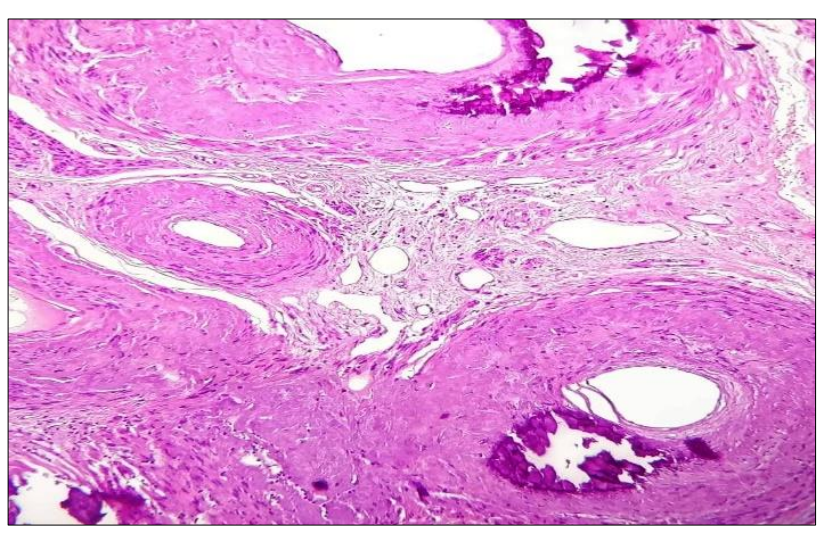

Figure 1: Calcification deposition around vessels indicating senescence, $\mathrm{H}$ and $\mathrm{E}, 40 \mathrm{X}$.

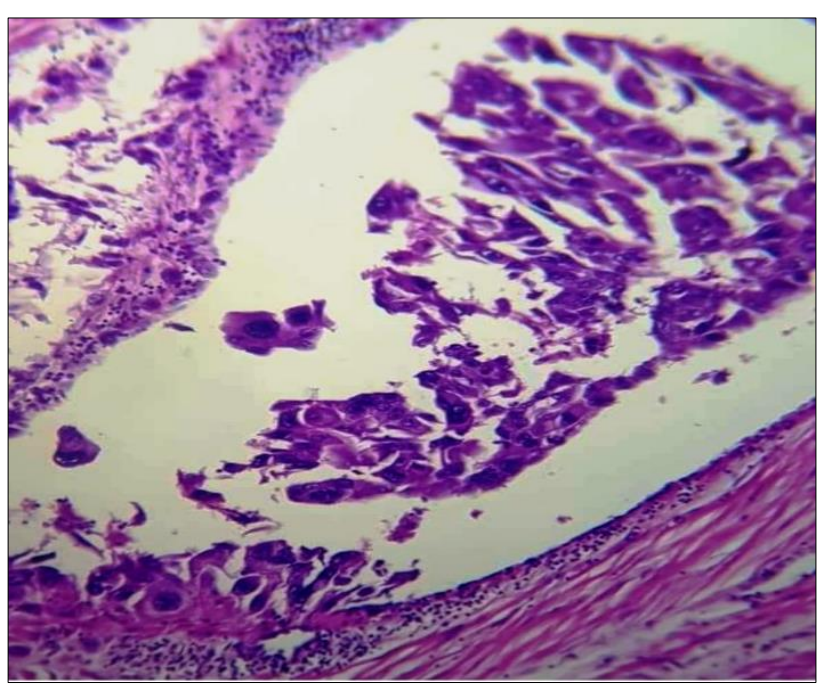

Figure 2: Presence of syncytial knots, $H$ and E, 40X.

Villous abnormalities were evaluated in terms of vascularity, cytotrophoblastic proliferation and syncytial knots (Figure 2) and basement membrane thickening as shown in Table 3 and 4.

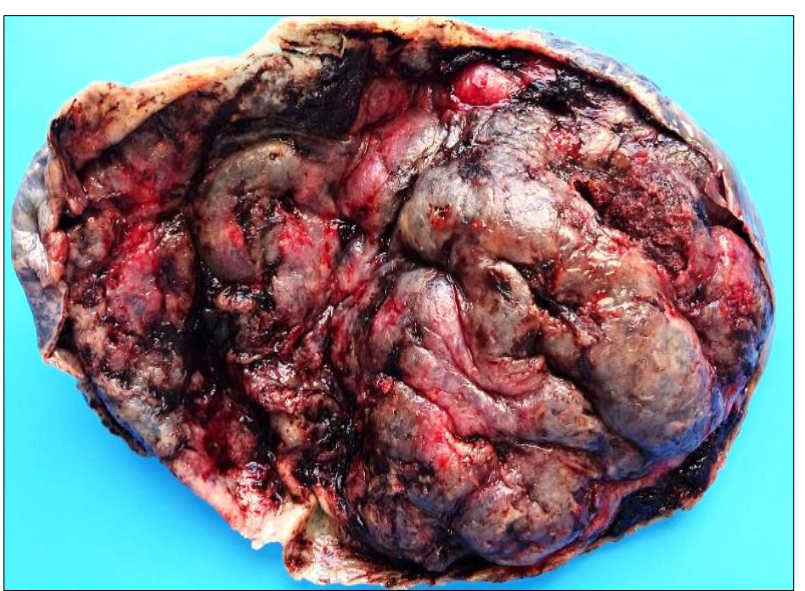

Figure 3: Gross appearance of placenta from preeclampsia showing increase in volume and congestion.

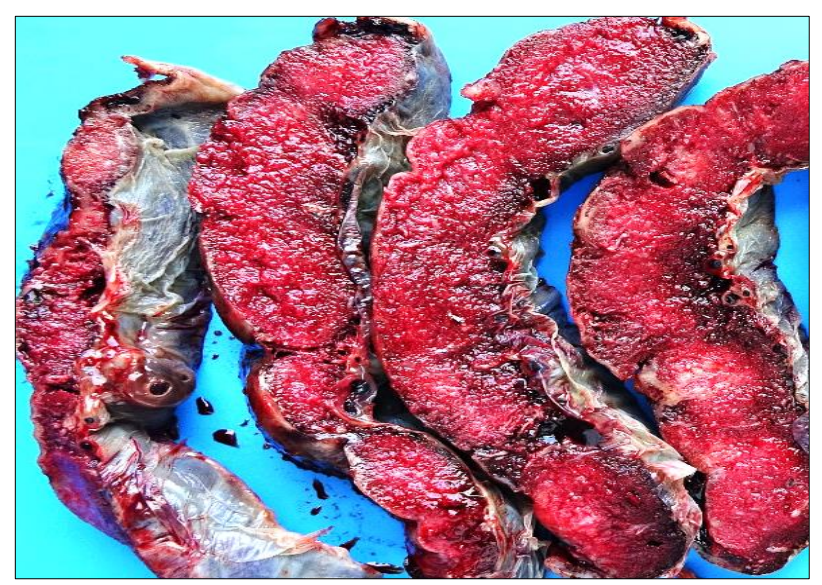

Figure 4: Gross image of placenta showing foci of infarction indicating hemodynamic disturbances. 


\section{DISCUSSION}

Preeclampsia is a clinical condition characterized by placental abnormality leading to maternal and fetal complications. ${ }^{1,2}$ Gestational trophoblastic disease is a broad entity comprising spectrum of placental lesions and its incidence is on higher margin in recent times. ${ }^{3,4}$ Placenta is a dynamic tissue rendered with a major function of supplying nutrients and blood supply to the fetus. ${ }^{5}$ Researchers had proposed that 'healthier the placenta so is the healthy pregnancy and rightly described as mirror of perinatal morbidity and mortality', ${ }^{6,7}$

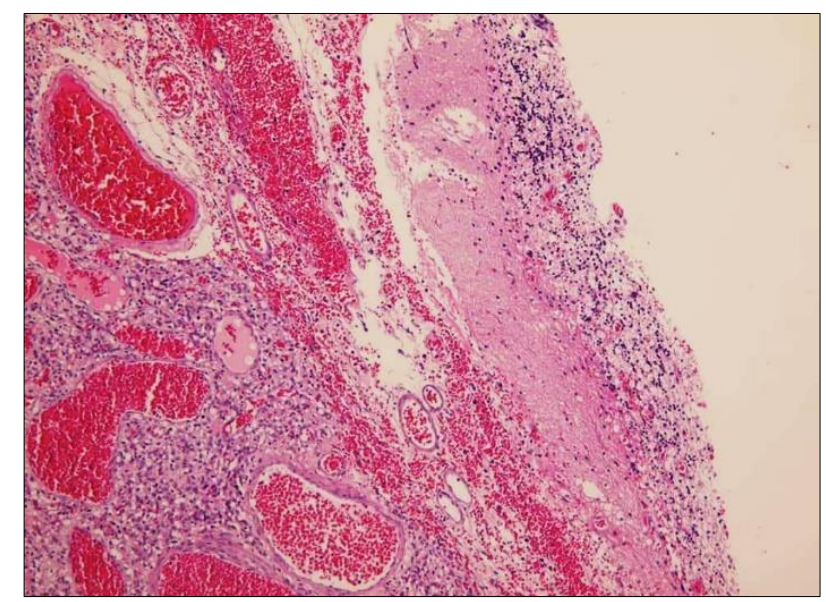

Figure 5: Fibrinous degeneration with congested vessels and inflammation, $H$ and $E, 10 X$.

Toxemic pregnancy encompasses wide range of complications and placental abnormalities is an indicator of the severity of toxemic status. ${ }^{8,9}$ Preeclampsia has deleterious impacts on placenta which can be demonstrated gross inspection as well as microscopic findings. ${ }^{10,11}$ The present study analyzed various placental changes on histomorphology in pre-eclamptic and toxemic pregnancies concurring with previous studies done by researchers as compared and shown in Table 5.

Table 5: Comparative metric of prior literatures in reference to present study.

\begin{tabular}{|ll|}
\hline $\begin{array}{l}\text { Studies observed by } \\
\text { researchers }\end{array}$ & Number of toxemic cases \\
\hline Madazali et al & 120 \\
\hline${\text { Lavinia et } \mathrm{al}^{6}}^{6}$ & 110 \\
\hline Memon $^{7}$ & 95 \\
\hline Verma et al & 126 \\
\hline Present study & 101 \\
\hline
\end{tabular}

\section{Gross abnormalities}

Researchers had observed that placenta obtained from preeclamptic patients tend to be smaller than those from normal pregnancies indicated by retarded fetomaternal ratio. In the present study, as depicted in Table 1, the placental weight is small in preeclamptic group (Group 2,
$3,4)$ compared to control group (Group 1) as shown in (Figure 3). The observations are in concordance with Verma et al. ${ }^{8}$

Among the observed cases 20 cases showed infarct which could be demonstrated grossly as a grey-white plaques Figure with granular surface indicating hemodynamic turbulence in placental circulation which eventually ends up with necrosis causing fetal hypoxia and neonatal morbidities (Figure 4).

\section{Retroplacental hematomas}

Retroplacental hematomas are not so uncommon in toxemic pregnancies and known to occur in 12 to $15 \% .^{12,13}$ It is characterized by spaces formed between basal plate of placenta and uterine wall starting from maternal aspect of placenta progressing towards fetal surface. ${ }^{13}$ It can be classified into older type usually seen firmly adhering to placental surface and fresh hematoma often tend to be present in maternal surface. The present study is in concordance with prior studies where 3 cases showed the condition. ${ }^{13}$

\section{Intervillous fibrin deposition}

Fibrin being a degenerative change especially around blood vessels, fibrin deposition around villi appears as white plaques and patches at the peripheral part giving a mottled appearance. Microscopically, these lesions show broadly separated villi entrapped within fibrin deposits filling the intervillous spaces. ${ }^{14,15}$ The major impact of perivillous deposition of fibrin is the involvement of $>30$ percent of surface area which disrupts the functioning of placenta in toxemic pregnancies. In the present study, fibrin deposition is noted among 36 cases and all the observed cases involved $<30$ percent of surface areas concurring with prior studies..$^{15}$

\section{End artery changes}

The peripheral villous structure of well-formed placenta usually possesses around three to five capillaries in the villus and based on the number they are categorized avascularity, hypo and hypervascularity and all the three categories occurring in pre-eclamptic pregnancies in variable proportion, the major reason being a sequelae of fetal artery thrombosis. In the present study, end artery changes are noted in 31 cases concurring with prior studies done by Veram etal. ${ }^{8}$

\section{Hydropic changes of villi}

Hydropic changes in villi is the characteristic abnormality that could be easily demonstrated on light microscopy and having access to special stain like periodic acid Schiff stain. Fetus whose placenta possess a marked increase in content of villi with thick trophoblastic basement membrane tend to show significant increase in hypoxia when compared to normal controls thus ensuring 
the concept that fetal hypoxia is due to abnormality in the placental structure rather than basement membrane changes. ${ }^{9,11}$

\section{Villous edema}

As a matter of well-known fact, that villous edema is a common factor associated with toxemic pregnancies, its incidence is associated with altered intervillous space thereby retarding maternal blood flow to the growing fetus leading to episode of clinical hypoxia. In the present study, villous edema is noted in 45 cases re-emphasizing the fact that it is common observation and cause for fetal complications in pre-eclamptic pregnancies. ${ }^{11,13}$

\section{Fibrinoid degeneration of villi}

Any fibrinous material observed on histology goes in favor of blood vessel pathology and in toxemic pregnancy it is demonstrated by pale eosinophilic material deposition at multiple points in villous trophoblasts and intervillous spaces (Figure 5). The incidence of villous fibrinoid necrosis is usually higher in placenta of pre-eclamptic patients and is a direct indicator of hemodynamic imbalance. In the present study, fibrinoid degeneration is noted in 29 cases and concurring with prior studies. ${ }^{15,16}$

\section{CONCLUSION}

The incidence of toxemic pregnancies and pre-eclamptic cases are on higher margin than assumed. The present study observed that placental pathology like infarction, calcification, fibrin deposition and hematoma are commoner in toxemic associated pregnancy rather than normal conditions. Histomorphology examination of placenta plays a vital role in assessing etiopathogenesis and mechanism of toxemic pregnancies. This aids the obstetrician to further manage subsequent sequelae and fix the complication to significant proportion.

\section{Funding: No funding sources}

Conflict of interest: None declared

Ethical approval: The study was approved by the Institutional Ethics Committee

\section{REFERENCES}

1. Benirschke K, Kaufmann P. Pathology of the human placenta. $2^{\text {nd }}$ ed. New York: Springer Verlag; 2010.

2. Udainia A, Jain ML. Morphological study of placenta in pregnancy induced hypertension with its clinical relevance. J Anat Soc India. 2001;50(1):247.
3. Fernando Arias. In: Practical guide to high-risk pregnancy and delivery, Mosby, Harcourt Asia Private Ltd., $2^{\text {nd }}$ Edition; 2009:184-185.

4. Pritchard JA, MacDonald PC. In William's Obstetrics, Appleton Century- Croft, New York; 2017:665-668.

5. Madazali, Lennon M. Effect of hypoxia on trophoblast in organ culture. Am J Obstet Gynaecol. 2010;107:1058.

6. Laviana, Scott A. Quantitative structural studies on human placentas associated with pre-eclampsia, essential hypertension and intrauterine growth retardation. Brit J Obstet Gynaec. 2005;92:714.

7. Memon E, Fox H. Pathology of the placenta. London: WB Saunders; 2016:477-481.

8. Verma E, Kalra R. Prenatal brain damage and placental infarction-an autopsy study. Dev Med Child Neurol. 2015;37:555-62.

9. Ashworth JR, Warren AY, Baker PN, Johnson IR. Loss of endothelium dependent relaxation in myometrial resistance arteries in pre-eclampsia. Brit J Obstet Gynaeco. 1997;104:1152-8.

10. Perrrin EVDK, Sander CM. Introduction: How to examine placenta and why. In: Perrin EVDK, ed. Pathology of placenta, $5^{\text {th }}$ ed New York. Churchil Livingstone Inc.; 1984:57-88.

11. Fox H. General pathology of placenta. Obstetrics and gynaecological pathology ed. Fox H. New York: Churchill Livingstone; 1995:1477-1508.

12. Nobis $P$, Das U. Placental morphology in hypertensive pregnancy. J Obstet Gynecol. 1990;40:166-9.

13. Sayeed M, Chakrawarti RN, Devi PK. A comparative study of placental villous changes in normal and abnormal pregnancies. J Obstet Gynaecol India. 2016;46:217-21.

14. Kalra VB, Aggarwal A, Sareen PM, Kalra R. Histopathological changes in placenta in toxaemia of pregnancy. J Obstet Gynaecol India. 2005;35:86-90.

15. Bhatia A, Sharma SD, Jalnawalla SF, Sagreiya K. A comparative study of placental and fetal outcome. Indian J Pathol Microbiol. 2011;24:277-83.

16. Mehrotra VG, Mukherjee K, Pande M, Gurtu P, Mukherjee M. The histological study of placentae in normal and abnormal pregnancy. J Obstet Gynaecol India. 2012;22:248-53.

Cite this article as: Samal R, Vaithy AK, Sowmya $\mathrm{S}$. Histomorphological analysis of placental changes of pre-eclampsia patients in a tertiary care hospital of Puducherry. Int J Reprod Contracept Obstet Gynecol 2020;9:2299-304. 